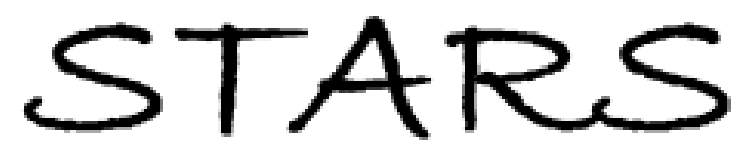

University of Central Florida

STARS

$1-1-1995$

\title{
Multisite Nature And Efficient Lasing At 1040 And 1302 Nm In Nd3+ Doped Potassium Yttrium Fluoride
}

\author{
X. X. Zhang \\ University of Central Florida \\ P. Hong \\ University of Central Florida \\ M. Bass \\ University of Central Florida \\ B. H. T. Chai \\ University of Central Florida
}

Find similar works at: https://stars.library.ucf.edu/facultybib1990

University of Central Florida Libraries http://library.ucf.edu

This Article is brought to you for free and open access by the Faculty Bibliography at STARS. It has been accepted for inclusion in Faculty Bibliography 1990s by an authorized administrator of STARS. For more information, please contactSTARS@ucf.edu.

\section{Recommended Citation}

Zhang, X. X.; Hong, P.; Bass, M.; and Chai, B. H. T., "Multisite Nature And Efficient Lasing At 1040 And 1302 Nm In Nd3+ Doped Potassium Yttrium Fluoride" (1995). Faculty Bibliography 1990s. 1521.

https://stars.library.ucf.edu/facultybib1990/1521

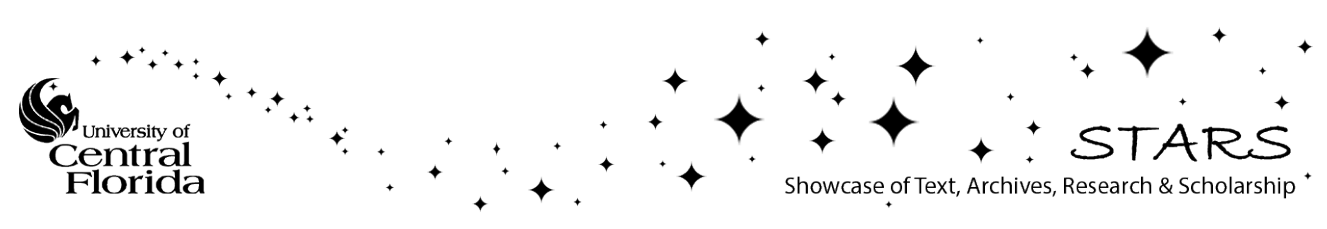




\section{Multisite nature and efficient lasing at 1041 and $1302 \mathrm{~nm}$ in $\mathrm{Nd}^{3+}$ doped potassium yttrium fluoride}

Cite as: Appl. Phys. Lett. 66, 926 (1995); https://doi.org/10.1063/1.113599

Submitted: 10 March 1994 . Accepted: 07 December 1994 . Published Online: 04 June 1998

X. X. Zhang, P. Hong, M. Bass, and B. H. T. Chai
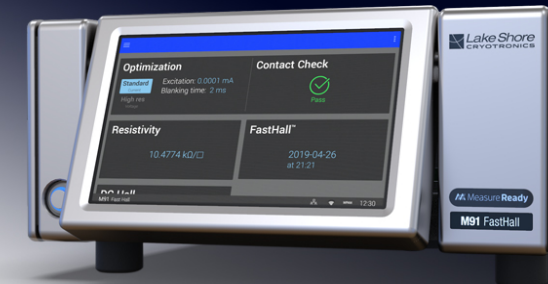

\section{Measure Ready} M91 FastHall ${ }^{\text {TM }}$ Controller

A revolutionary new instrument for complete Hall analysis See the video 0

Lake Shore 


\title{
Multisite nature and efficient lasing at 1041 and $1302 \mathrm{~nm}$ in $\mathrm{Nd}^{3+}$ doped potassium yttrium fluoride
}

\author{
X. X. Zhang, P. Hong, M. Bass, ${ }^{\text {a) }}$ and B. H. T. Chaib) \\ CREOL-Center for Research and Education in Optics and Lasers, University of Central Florida, \\ Orlando, Florida 32826
}

(Received 10 March 1994; accepted for publication 7 December 1994)

\begin{abstract}
Lasing of $\mathrm{Nd}^{3+}$ ions in different crystallographic sites of $\mathrm{KYF}_{4}$ has been demonstrated to occur at different wavelengths. Low threshold, high efficiency lasing performance at 1041 and $1302 \mathrm{~nm}$ were achieved under selective pumping conditions. The stimulated emission cross section at $1041.2 \mathrm{~nm}$ was estimated to be $2.6 \times 10^{-19} \mathrm{~cm}^{2}$ and the radiative lifetime was found to be $600 \mu \mathrm{s}$. (C) 1995 American Institute of Physics.
\end{abstract}

$\mathrm{KYF}_{4}(\mathrm{KYF})$ was considered as an attractive $\mathrm{Nd}^{3+}$ host for diode laser pumping ${ }^{1}$ because $\mathrm{Nd}^{3+}$ ions in this crystal have a broader absorption band in the $800 \mathrm{~nm}$ region and a longer fluorescence lifetime than in either $\mathrm{Y}_{3} \mathrm{Al}_{5} \mathrm{O}_{12}(\mathrm{YAG})$ or $\mathrm{LiYF}_{4}$ (YLF). It was also an interesting material because the lasing wavelength of this crystal was among the shortest wavelengths available for $\mathrm{Nd}^{3+}$ ions in crystals, However, earlier work ${ }^{2}$ did not show much promise for this crystal. A slope efficiency of only $30 \%$ was obtained with a high threshold of $300 \mathrm{~mW}$ for $\mathrm{cw}$ Ti:sapphire laser pumped laser operation. $^{2}$ In this letter, we report the multiwavelength lasing of $\mathrm{Nd}^{3+}$ ions resulting from the multisite nature of $\mathrm{KYF}_{4}$. By pumping the crystal at selected wavelength, low threshold, high efficiency lasing was achieved at both 1041 and $1302 \mathrm{~nm}$. The discrepancies between the present results and those previously reported will be discussed.

High quality $\mathrm{Nd}^{3+}: \mathrm{KYF}_{4}$ crystals were grown by the conventional Czochralski method. The melting point of $\mathrm{KYF}_{4}$ is slightly higher than $800{ }^{\circ} \mathrm{C}$. The melt composition was $43 \% \mathrm{YF}_{3}$ and $57 \% \mathrm{KF}$. The typical crystal growth parameters are pull rate $=0.5 \mathrm{~mm} / \mathrm{h}$ and rotation $=15 \mathrm{rpm}$. The growth conditions are discussed in detail elsewhere. ${ }^{3}$

The room-temperature emission spectra of $\mathrm{Nd}^{3+}: \mathrm{KYF}_{4}$ in the $1 \mu \mathrm{m}$ region are shown in Fig. 1. They were obtained by exciting a sample containing 1.2 at. $\% \mathrm{Nd}^{3+}$ with a cw Ti:sapphire laser. The spectral width of the laser was $\sim 2$ $\mathrm{cm}^{-1}$. The emission in this region consists mainly of two peaks centered at 1041 and $1054 \mathrm{~nm}$. The excitation wavelengths, 799.4 and $804.5 \mathrm{~nm}$, so chosen to maximize the relative intensity of the peak at $1041 \mathrm{~nm}$ for curve a and the peak at $1054 \mathrm{~nm}$ for curve b in Fig. 1, respectively, correspond to the two main absorption peaks in the $800 \mathrm{~nm}$ region as shown in Fig. 2. As seen in Fig. 1 the relative intensity of the two emission peaks changes with excitation wavelength. This indicates that the emissions originate from different electronic centers. The emission dynamics of these two features were studied in a dilute sample containing 0.18 at. \% $\mathrm{Nd}^{3+}$ at $15 \mathrm{~K}$ using a $Q$-switched $\mathrm{Cr}$ :LiSAF laser tuned to 799.6 and $805 \mathrm{~nm}$ for 1041 and $1054 \mathrm{~nm}$ emission, respectively. As shown in Fig. 3, the emission dynamics differ for

a) Also: Departments of Physics and Electrical and Computer Engineering.

${ }^{b}$ Also: Departments of Physics, Electrical and Computer Engineering, and Mechanical Engineering. each feature, confirming again that they are of different electronic origin. Our detailed low temperature, selective excitation experiments indicate that each of these two peaks actually consists of a group of lines: two for the $1041 \mathrm{~nm}$ peak and four for the $1054 \mathrm{~nm}$ peak. However, no difference in the emission dynamics was detected within our experimental accuracy for different lines within each group indicating that lines within each group have similar spectroscopic properties. We therefore classify the groups into two classes according to the previous notation. ${ }^{4}$ Class I for emission in the group peaked at $1041 \mathrm{~nm}$ and class II for emission peaked at $1054 \mathrm{~nm}$. The corresponding classification in the absorption spectrum is indicated in Fig. 2. The emission decays shown in Fig. 3 are nearly exponential with a lifetime of 600 and $780 \mu$ s for class I and class II emission, respectively. Careful measurements indicate that the lifetime of each class does not change with temperature. Since these decay times are obtained with a dilute sample at low temperature and they do not change with temperature, they can be regarded as the radiative lifetime of each class. Both selective excitation

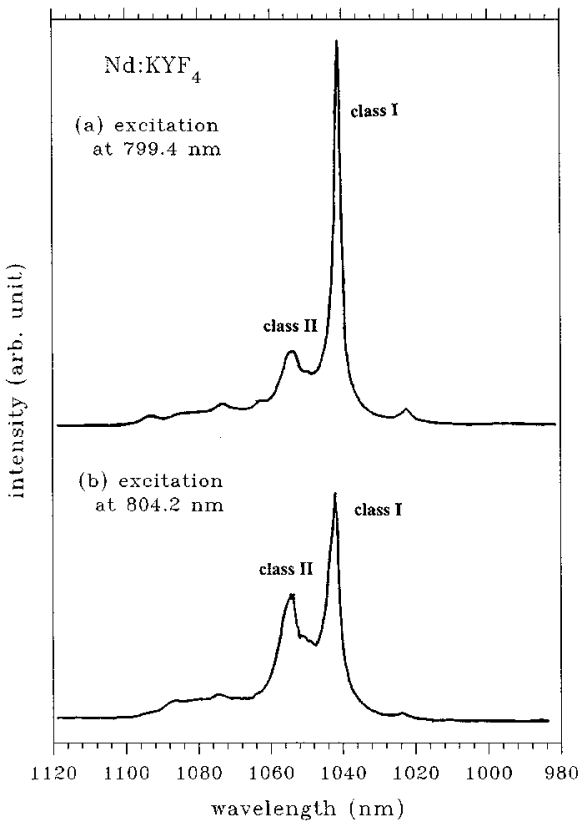

FIG. 1. Room-temperature emission spectra of $\mathrm{Nd}^{3+}: \mathrm{KYF}_{4}$ in the $1 \mu \mathrm{m}$ region using excitation wavelengths of (a) $799.4 \mathrm{~nm}$ and (b) $804.2 \mathrm{~nm}$. 


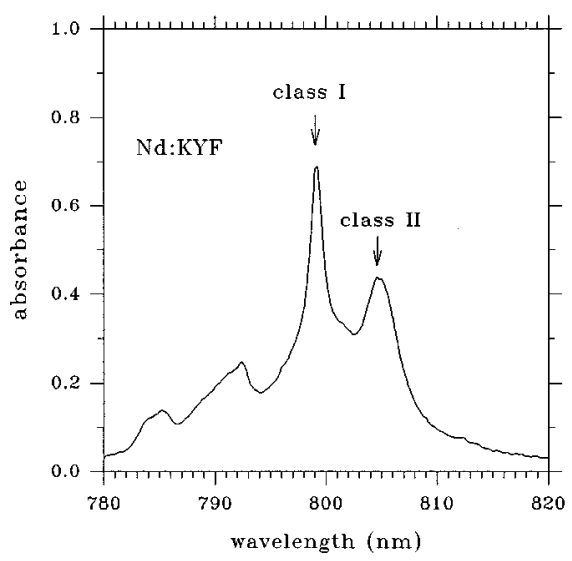

FIG. 2. Room-temperature absorption spectrum of $\mathrm{Nd}^{3+}: \mathrm{KYF}_{4}$ in the 800 $\mathrm{nm}$ region. Arrows indicate the excitation wavelengths used in obtaining the emission spectra shown in Fig. 1.

spectroscopy and dynamics measurements indicated that energy transfer occurs only from class I to class II at temperatures lower than $30 \mathrm{~K}$ and occurs in either direction at higher temperatures. ${ }^{5}$

Lasing performance was tested with a 3-mm-long $\mathrm{KYF}_{4}$ crystal containing 1.2 at. $\% \mathrm{Nd}^{3+}$. The roomtemperature decay time of this sample was found to be 444 $\mu$ s for class I and $538 \mu$ s for class II emissions. Its end surfaces contained the crystalline $c$-axis and were polished flat and parallel to each other. The crystal was antireflection coated at around $1.05 \mu \mathrm{m}$. The laser cavity consisted of a 5 $\mathrm{cm}$ radius of curvature high reflector and a flat output coupler with transmission up to $5 \%$. The cavity length was about $4.7 \mathrm{~cm}$. Pulsed and $\mathrm{cw}$ operation were studied with excitation by a long-pulse $(\sim 100 \mu \mathrm{s}) \mathrm{Cr}$ :LiSAF laser and a cw Ti:sapphire laser, respectively. Both pump lasers were tunable with a spectral width of $\sim 0.1 \mathrm{~nm}$ for the Ti:sapphire laser and $\sim 1$ $\mathrm{nm}$ for the Cr:LiSAF laser. The pump sources were focused into the crystal with a $10 \mathrm{~cm}$ focal length lens.

The laser output was $\pi$-polarized and occurred at a wavelength which depended on the pump wavelength. Maximum slope efficiencies and lowest thresholds were obtained when pumping at $799.6 \mathrm{~nm}$, which results in lasing at 1041.2

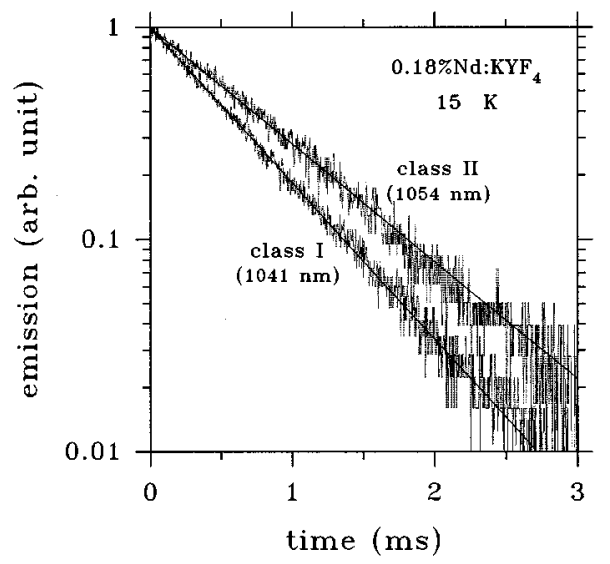

FIG. 3. Emission decay curves for two different classes of $\mathrm{Nd}^{3+}$ ions in $\mathrm{KYF}_{4}$ at $15 \mathrm{~K}$. $\mathrm{nm}$. Under this pumping condition and for a $5 \%$ output coupler the slope efficiency and threshold were 52\% and 9.4 $\mathrm{mW}$ for cw operation and $63 \%$ and $38 \mu \mathrm{J}$ for long-pulse operation. When the pump source was tuned, a small amount from $799.6 \mathrm{~nm}$ to either a shorter or longer wavelength, the laser output occurred at $1041.8 \mathrm{~nm}$. When the pump wavelength was tuned further (about $1 \mathrm{~nm}$ away) in either direction, lasing output occurred at two wavelengths, 1041.8 and $1054.6 \mathrm{~nm}$, simultaneously. In this case, the lasing threshold was higher and the laser output lower than in the case of single wavelength lasing for the same absorbed power (energy).

The transition of $\mathrm{Nd}^{3+}$ between ${ }^{4} F_{3 / 2}$ and ${ }^{4} I_{13 / 2}$ in $\mathrm{KYF}_{4}$ results in emission peaked at $1302 \mathrm{~nm}$ for class I and at $1307 \mathrm{~nm}$ for class II. Our emission measurements indicate that the branching ratio of the ${ }^{4} F_{3 / 2} \rightarrow{ }^{4} I_{13 / 2}$ for transition to the ${ }^{4} F_{3 / 2} \rightarrow{ }^{4} I_{11 / 2}$ transition is quite high, in contrast to the previous reported results based on Judd-Ofelt calculations. $^{2}$ The peak intensity ratio of the $1.3 \mu \mathrm{m}$ to the $1 \mu \mathrm{m}$ emission was measured to be 0.28 for class I and 0.40 for class II. These ratios are quite high compared with the same ratios in most $1.3 \mu \mathrm{m}$ laser materials. We therefore, tested the $1.3 \mu \mathrm{m}$ lasing using the same crystal mentioned above and a $5 \%$ output coupler. In this case, lasing occurred at 1302 and 1307 $\mathrm{nm}$ either separately or simultaneously depending on the pump wavelength. The best performance was achieved at $1302 \mathrm{~nm}$ when pumped at $799.6 \mathrm{~nm}$. The long-pulse threshold in this case was $190 \mu \mathrm{J}$ and a slope efficiency of higher than $50 \%$ was obtained. $\mathrm{Nd}^{3+}: \mathrm{KYF}_{4}$ performs very well at $1302 \mathrm{~nm}$ considering that the quantum-limited slope efficiency in this case is only about $60 \%$. However, cw lasing was not achieved with the maximum pump power of about $200 \mathrm{~mW}$ available at the time of this particular experiment.

In order to estimate the stimulated emission cross section of $\mathrm{Nd}^{3+}: \mathrm{KYF}_{4}$ at $1041.2 \mathrm{~nm}$, comparative lasing studies were made with $\mathrm{Nd}^{3+}: \mathrm{LiYF}_{4}$ (YLF), a well-known laser crystal. The absorbed power at lasing threshold can be expressed as follows: ${ }^{6}$

$$
P_{t h}=\frac{\pi h \nu_{p} \delta}{4 \sigma_{e} \tau \eta_{p}}\left(w_{0}^{2}+w_{p}^{2}\right),
$$

where $h \nu_{p}$ is the pump photon energy, $\eta_{p}$ the pump quantum efficiency, $\tau$ the upper manifold decay time, $\sigma_{e}$ the effective stimulated emission cross section, $\delta$ the roundtrip loss which includes both internal and external losses, and $w_{0}$ and $w_{p}$ the beam radii of the laser cavity mode and the pump beam, respectively. The pump quantum efficiency, the number of ions in the upper manifold created by one absorbed photon, should be near unity and therefore about the same for both crystals. In addition, $w_{0}$ and $w_{p}$ are the same for both lasers since the cavity was the same for both lasers. As a result, the effective stimulated emission cross section of $\mathrm{Nd}^{3+}$ :KYF can be estimated from that of $\mathrm{Nd}^{3+}$ :YLF by comparing the thresholds, the pump wavelengths, the losses, and the upper manifold decay times of both crystals. Using $5 \%$ output coupling a cw laser threshold power of $11.5 \mathrm{~mW}$ wa obtained for a $1.2 \% \mathrm{Nd}^{3+}$ :YLF crystal lasing at $1.047 \mu \mathrm{m}$ (pumped at 797 $\mathrm{nm}$ ) compared to $9.4 \mathrm{~mW}$ for $\mathrm{Nd}^{3+}: \mathrm{KYF}$ lasing at 1041.2 $\mathrm{nm}$ when pumped at $799.6 \mathrm{~nm}$. The emission decay time of 
this $\mathrm{Nd}^{3+}$ :YLF crystal $442 \mu \mathrm{s}$ is almost the same as that of the $\mathrm{Nd}^{3+}: \mathrm{KYF}$ at $1041.2 \mathrm{~nm}, 444 \mu \mathrm{s}$. The double-pass passive loss $(\delta)$ can be obtained by studying the measured slope efficiency $(\eta)$ as a function of output coupler transmission (T) through the following relation ${ }^{7}$

$$
\eta=\eta_{0} T /(T+\delta),
$$

where $\eta_{0}$ is the intrinsic slope efficiency. We found that $\eta_{0}=56.6 \%$ and $\delta=0.5 \%$ for $\mathrm{Nd}^{3+}: \mathrm{KYF}$ in cw operation at $1041.2 \mathrm{~nm}$ when selectively pumped at $799.6 \mathrm{~nm}$ and $\eta_{0}=76 \%$ and $\delta=0.45 \%$ for the $\mathrm{Nd}^{3+}$ :YLF crystal. Comparing the above mentioned data for both crystals the effective emission cross section of $\mathrm{Nd}^{3+}: \mathrm{KYF}_{4}$ at $1041.2 \mathrm{~nm}(\pi$ polarization) was estimated to be $2.6 \times 10^{-19} \mathrm{~cm}^{2}$. We obtained this cross section using the published emission cross section of $\mathrm{Nd}^{3+}$ :YLF, $1.96 \times 10^{-19} \mathrm{~cm}^{2}$ at $1.047 \mu \mathrm{m}$ for $\pi$ polarization. ${ }^{8}$

It is not surprising that the emission cross section obtained from our selective lasing results is more than 6 times that obtained in Ref. 2 from a Judd-Ofelt calculation using multisite absorption and emission spectra. Since the absorption and emission spectra obtained when the sites are undifferentiated appear to be much broader than those obtained with site selective excitation, the relative peak emission intensity at the lasing wavelength appears to be weaker. As a result, the Judd-Ofelt calculations using such data will result in weaker transition strengths and therefore lower emission cross sections than the intrinsic values for each class. It is also easy to understand our relatively high emission cross section (higher than that of $\mathrm{Nd}$ :YLF) since our site selective spectroscopy indicates that the emission spectrum of each individual site is dominated by a single sharp peak. ${ }^{5}$

Studies of the structure of $\mathrm{KYF}_{4}{ }^{9,10}$ revealed that there are six distinct $\mathrm{Y}^{3+}$ sites in $\mathrm{KYF}_{4}$ and that these sites can be classified into two groups, although there is a difference between Refs. 9 and 10 in the classification of the two groups. Our results indicating two classes of dopant sites, are consistent with such results based on structural analysis.

Considering the multisite nature of $\mathrm{KYF}_{4}$ it is then easy to understand the differences between previous results and ours. Our selective dynamics studies revealed that the two classes of sites have very different radiative lifetimes for the ${ }^{4} F_{3 / 2}$ manifold and that these lifetimes do not depend on temperature. The latter is consistent with most $\mathrm{Nd}^{3+}$ systems in which the contribution of temperature dependent nonradiative processes to the ${ }^{4} F_{3 / 2}$ decay time is negligible. As a result of experiments lacking selective excitation and detection of the individual classes of emitters, Ref. 2 reached the conclusion that the decay time decreases with increasing temperature. Consequently, it implied that the quantum efficiency of $\mathrm{Nd}^{3+}$ in $\mathrm{KYF}_{4}$ is no more than $80 \%$ even in the absence of concentration quenching. Such a low value of quantum efficiency would make it difficult to understand our efficient lasing results. Our measured radiative decay time is $600 \mu$ s for class I emission and $780 \mu$ s for class II emission. Reference 4 gave a decay time of $750-850 \mu$ s for class I and 680-720 $\mu$ s for class II. We note that the crystal used in Ref. 4 has a $\mathrm{Nd}^{3+}$ concentration of about 0.6 at. \% so that the decay time given for class II in Ref. 4 is consistent with our value for a similarly doped sample. However, the decay time value for class I differs very much from ours. Since a chopped cw Ti:sapphire laser was used in Ref. 4, the sample temperature could easily reach a temperature higher than 30 $\mathrm{K}$ even though the nominal experimental temperature was said to be $5 \mathrm{~K}$. When the crystal temperature is higher than $30 \mathrm{~K}$ the energy transfer from classes II to I sites occurs as we have observed and mentioned earlier. In this case, the emission dynamics of class I will consist of an initial rise when class II is excited. If a slowly chopped cw source was used in dynamics measurements and if the source was not carefully tuned to excite only class I sites such an initial rise would exist but would go undetected. The result could be a measured decay time that is longer than the real one.

In summary, we have demonstrated the multisite nature of $\mathrm{Nd}^{3+}: \mathrm{KYF}_{4}$ by spectroscopic and lasing studies. We have found that the two classes of $\mathrm{Nd}^{3+}$ ions in $\mathrm{KYF}_{4}$ have different radiative lifetimes and that these lifetimes do not change with temperature. We have also demonstrated simultaneous lasing from $\mathrm{Nd}^{3+}$ ions in different sites and shown that by pumping only one class of dopant ions, low threshold, high efficiency lasing performance can be achieved. The emission cross section for the particular site which lases at $1041.2 \mathrm{~nm}$ was found to be $2.6 \times 10^{-19} \mathrm{~cm}^{2}$ and is even higher than that of Nd:YLF. Our results demonstrate the inapplicability of Judd-Ofelt calculations to multisite systems. We believe that the poor lasing results reported previously ${ }^{2}$ resulted from nonoptimized pumping. The lasing wavelengths, 1041 and $1302 \mathrm{~nm}$, are among the shortest reported for $\mathrm{Nd}^{3+}$ ions in crystals, which may enable some wavelength specific applications for this crystal. Also some interesting applications may be found to take advantage of the simultaneous dual-wavelength lasing.

This work was supported by the Advanced Research Projects Agency (ARPA) and by the Florida High Technology and Industry Council. The fabrication of crystals by Lightning Optical Corp. is gratefully appreciated.

${ }^{1}$ M. A. Dubinskii, N. M. Khaidukov, I. G. Garipov, L. N. Dem’yanets, A. K. Naumov, V. V. Semashko, and V. A. Malyusov, J. Mod. Opt. 37, 1355 (1990).

${ }^{2}$ T. H. Allik, L. D. Merkle, R. A. Utano, B. H. T. Chai, J.-L. V. Lefaucheur, H. Voss, and G. J. Dixon, J. Opt. Soc. Am. B 10, 633 (1993).

${ }^{3}$ B. Chai, J. Lefaucheur, A. Pham, G. Lutts, and J. Nicholls, Proc. SPIE 1863, 131 (1993).

${ }^{4}$ Y. Yamaguchi, K. M. Dinndorf, H. P. Jenssen, and A. Cassanho, OSA Proceedings on Advanced Solid-State Lasers, edited by A. A. Pinto and T. Y. Fan (Optical Society of America, Washington, DC, 1993), Vol. 15, pp. 36-40.

${ }^{5}$ X. X. Zhang, P. Hong, M. Bass, and B. H. T. Chai, OSA Proceedings on Advanced-Solid-State Lasers, edited by T. Y. Fan and B. H. T. Chai (Optical Society of America, Washington, DC, 1993), Vol. 20, pp. 37-40.

${ }^{6}$ T. Y. Fan and R. L. Byer, IEEE J. Quantum Electron. QE-24, 895 (1988).

${ }^{7}$ J. A. Caird, S. A. Payne, P. R. Staver, A. J. Ramponi, L. L. Chase, and W. F. Krupke, IEEE J. Quantum Electron. QE-24, 1077 (1988).

${ }^{8}$ J. R. Ryan and R. Beach, J. Opt. Soc. Am. B 9, 1883 (1992).

${ }^{9}$ S. Aleonard, Y. Le Fur, L. Pontonnier, M. F. Gorius, and M. Th. Roux, Ann. Chim. Fr. 3, 417 (1978)

${ }^{10}$ Y. Le Fur, N. Khaidukov, and A. Aleonard, Acta Crystallogr. C 48, 978 (1992). 